Article

\title{
Characterization of Air Voids Distribution in the Open-Graded Asphalt Mixture Based on 2D Image Analysis
}

\author{
Guangji Xu ${ }^{1} \mathbb{D}$, Xiao Chen ${ }^{1}$, Xiaoming Huang ${ }^{1}$, Tao Ma ${ }^{1, * \mathbb{D}}$ and Wei Zhou ${ }^{2}$ \\ 1 School of Transportation, Southeast University, Nanjing 211189, Jiangsu, China; \\ guangji_xu@seu.edu.cn (G.X.); xche@seu.edu.cn (X.C.); huangxm@seu.edu.cn (X.H.) \\ 2 JSTI Group, Nanjing 211189, Jiangsu, China; lygzhouw@126.com \\ * Correspondence: matao@seu.edu.cn
}

Received: 4 September 2019; Accepted: 25 September 2019; Published: 2 October 2019

\begin{abstract}
The air voids distribution has a significant effect on the pavement performance related distresses such as rutting, cracking, moisture damage and permeability. However, most studies only quantified the air voids by average content, ignoring the heterogeneity inside the materials. This study focuses on the heterogeneity of air voids distribution inside the open-grade asphalt mixture based on 2D image analysis. Equivalent aperture is proposed to measure the area of each air void. Results showed that along both vertical and horizontal sections inside the open-grade asphalt mixture, the number of voids with $0 \sim 2 \mathrm{~mm}$ equivalent aperture would have a great impact on the total number of voids, while large amounts of small voids would not significantly affect the total voids number. Additionally, voids with $0 \sim 4 \mathrm{~mm}$ equivalent aperture account for the largest proportion, and when the equivalent aperture is beyond $4 \mathrm{~mm}$, the number of voids would decrease as the equivalent aperture increases, regardless of the void areas. Furthermore, in both vertical and horizontal sections, as the equivalent aperture increases, the speed to accumulate voids area would firstly increase and then decrease. As the equivalent aperture increases, the contribution to the total voids area would increase accordingly, and it would approach the peak when the equivalent aperture reaches about $8 \mathrm{~mm}$.
\end{abstract}

Keywords: air voids; voids number; equivalent aperture; accumulated voids number; accumulated voids area

\section{Introduction}

Air voids have a significant influence on the mechanical properties of asphalt mixtures. It is well established in many pieces of literature that air voids distribution can be a major factor which affects asphalt pavement performance, such as cracking, rutting, fatigue and moisture damage [1-4]. Some researchers found that under the same air voids, different air voids distribution can lead to different pavement performances [2,5]. Except for pavement performances, in open-graded pavements, air voids have a strong relationship with field permeability, and a mixture's nominal maximum aggregate size would greatly affect the permeability characteristics of the pavement [6]. Due to the lack of laboratory techniques to capture the air voids distribution in pavements, most of the research results are based on the average air voids content, no matter in pavement designing or specifying asphalt mixtures $[7,8]$. The current Superpave mixture design procedure is based on developing mixtures that attain certain average percent air voids at different compaction levels. However, quantifying the air voids by an average value means assuming the material to be homogeneous, while materials with the same air voids may have different distributions of air voids, which may lead to materials showing different properties [9]. Castillo and Caro (2019) also argued that taking the spatial variability of material properties into consideration is helpful to obtain a better insight into the actual structural 
reliability of the pavements [10]. Thus, the testing results of some specimens which have uneven air voids distribution would lead to certain variations in mechanical properties, affecting the testing reliability and misleading the material response [11]. To address the non-uniform distribution of air voids in materials, it is necessary to characterize and quantify the air voids inside the materials.

In order to capture the internal structure of asphalt mixtures and evaluate the effects of air void distribution, X-ray Computed Tomography (CT) and digital camera processing have been widely used non-destructive imaging technologies, which could provide a 2D or 3D image of the internal structure of a solid object [12]. From the digital camera or CT image processing, the location or coordinates of aggregates, reconstructed pore geometry, void-distribution segregation, the two-or three-dimensional internal structure of hot-mix asphalt or some distresses like cracking can be obtained [13-18]. As an increasing number of researchers have analyzed the asphalt pavement from the microstructure perspective [19-23], some of them have applied digital camera and CT image processing in the field of asphalt pavement, especially in terms of air voids. You (2009) analyzed the air voids distribution along the height using the X-ray computed tomography and predicted the dynamic modulus of the asphalt mixture [24]. Shashidhar (2000) used three-dimensional X-ray computed tomography for non-destructive evaluation of air void distribution and found that the rutting performance of mixes could be qualitatively related to the aggregate structure [25]. Besides, Mahmud et al. (2017) used virtual cut section to investigate the air voids properties and found that the air voids within the porous asphalt mixtures were homogeneously distributed with an elongated shape [26].

Nowadays, more and more researchers tend to study the effect of air voids distribution on the asphalt mixture performances, and the heterogeneity of air voids distribution has been proved to be related to material properties. Investigating the air voids distribution inside the materials could provide the outline of the structure, which would further be related to the asphalt mixture performances. Therefore, the objective of this research is to study the air voids distribution of the material, including its number and area magnitude, which could be related to mixture characteristics and pavement performances in the future.

In this study, OGFC samples with the size $300 \mathrm{~mm} \times 300 \mathrm{~mm} \times 50 \mathrm{~mm}$ were made under a specific open-grade design, they were cut into many regular sections and their vertical and horizontal profiles were scanned by a digital camera with 800 pixels per inch (ppi) resolution. Photoshop and MATLAB software were used to process the images. The concept of the equivalent aperture was proposed to study the area of each void and the air voids distribution was analyzed in both vertical and horizontal sections.

\section{Materials and Methods}

\subsection{Materials and Sample Preparation}

In this study, an 800 ppi digital camera was used to scan the materials. OGFC samples with size $300 \mathrm{~mm} \times 300 \mathrm{~mm} \times 50 \mathrm{~mm}$ were made based on the asphalt content and aggregate gradation of Wuzhoudadao permeable pavement in Shanghai, China. Two of them were dissected horizontally and the rest were dissected vertically. The gradation is OGFC-13 and the passing percentage of each sieve size is shown in Figure 1. The aggregates were basalt and the asphalt content was $4.9 \%$, compromised by $70 \#$ neat asphalt with $12 \%$ TPS. The air voids of the mixtures were $21.6 \%$, which was measured according to ASTM D1188. 


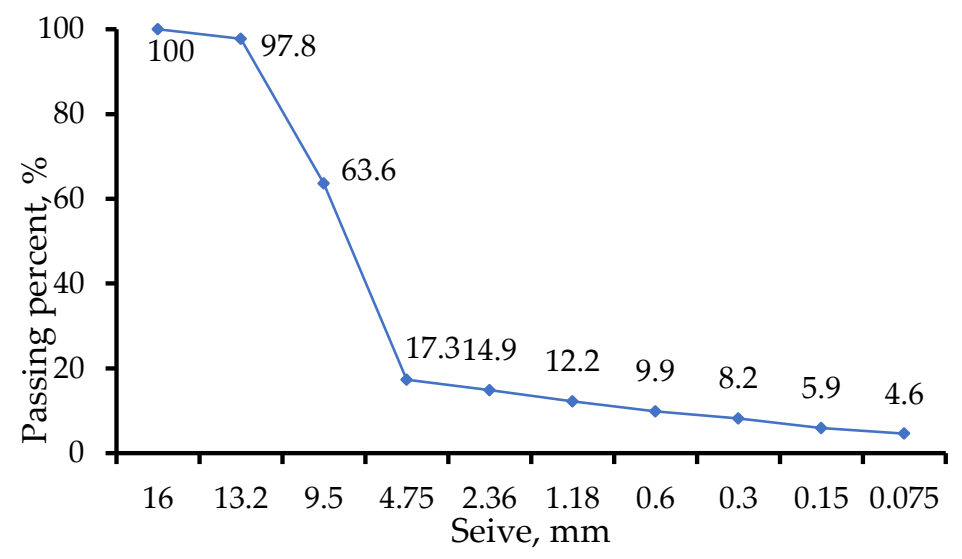

Figure 1. Gradation curve.

The samples were dissected according to Figure 2. Firstly, each sample was cut into six small specimens along the vertical direction, then each small specimen was cut horizontally. After that, the same scanner was used to scan the profile. The vertical and horizontal section numbers were shown in Figure 2.

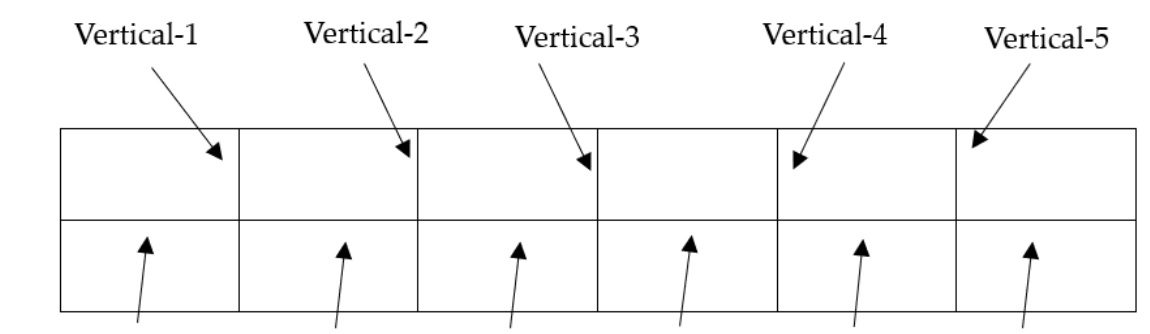

Horizontal-1 Horizontal-2 Horizontal-3 Horizontal-4 Horizontal-5 Horizontal-6

Figure 2. Dissection Direction.

Research activities of this study involve four steps. The first step is making specimens and incising them both vertically and horizontally. Then using the digital camera to scan each profile followed by using painting software and MATLAB to extract air voids structure. Subsequently, calculating the air voids and conducting analysis.

\subsection{Digital Camera Scan}

\subsubsection{Image Acquisitions}

In this study, the profiles of the specimens were scanned, which is easy, cheap, and feasible to study the internal pore diameter distribution. After dissecting the OGFC samples, Figure 3 shows a typical image obtained by a digital camera with a resolution of 800 ppi. Compared to the real profile of specimens, it could be found that the darkest color in mixture scanned profiles corresponds to the air void, the shallowest color patterns are aggregates and the rest is the asphalt mortar. 


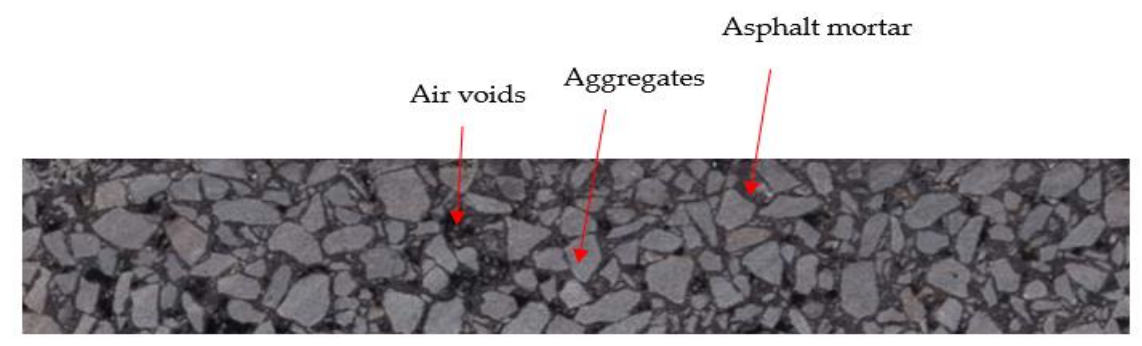

Figure 3. Initial Digital Image.

\subsubsection{Image Contrast Adjustment}

The scan image shown in Figure 3 is difficult to distinguish the boundary of each kind of component. It is necessary to increase the discrimination of the image in order to do further research, thus, the photoshop software was applied to process the scanned images. The black contrast degree was enhanced in the image to make the difference between voids, aggregates, and asphalt mortar more distinct. The image after processing is shown in Figure 4. Note that there are some white dots among air voids patterns (black areas), which represent the aggregates behind the voids.

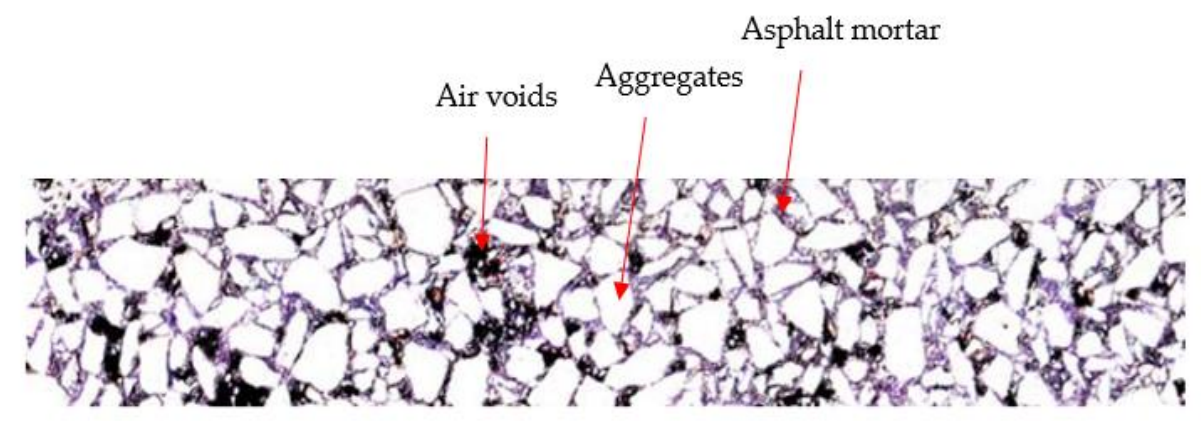

Figure 4. Adjusted Digital Image.

\subsubsection{Image Denoising}

To study the distribution of the air voids, MATLAB software was used to extract the voids and calculate voids structure-related parameters. The images processed by photoshop software were imported to MATLAB and transferred into gray images. In gray images, the black color was used as the reference color in order to extract voids patterns which were in black areas, and each pixel had a different saturability from $0 \%$ (white) to 100\% (black). The grayscale value was quantized into 256 grayscale levels ranging from 0 to 255 . The smaller the value was, the darker the color would be. However, there are some relatively dark points in aggregates and asphalt mortar areas among gray images, which are called noisy points and those noisy components must be eliminated before it can be used for further process or analysis. Therefore, image denoising was indispensable in this study. In this paper, median filtering was adopted to reduce the noise. This method can restrain disturbing pulses and points and keep the image edge better, which is more effective than the convolution method when the goal is to simultaneously reduce noise and preserve edges $[27,28]$. In MATLAB, median filtering could be achieved by function medfilt 2 which performs the images in two dimensions, each output pixel contains the median value in a 3-by-3 neighborhood around the corresponding pixel in the input image [28].

\subsubsection{Image Segmentation and Voids Extraction}

The original image was converted into a binary image which only included black and white colors. The pixels having a high gray value would become white when its value was above the threshold level, while all other pixels would become black [29]. White and black pixels received respective values of 1 and 0 . Due to the high resolution of the digital camera, the boundary of the picture has its own pixels, 
the boundary pixels would also receive values of 1 and 0 and then display black or white. Thus, the key is to select an optimal threshold. In this paper, the optimal threshold was obtained by function graythresh in MATLAB [30]. According to the function result, a good segmentation effect could be gained when the threshold was set by 35 , as shown in Figure $5 \mathrm{a}$. The gray value was assigned to be 0 when they were no more than 35 and to be 1 when they were more than 35 . Consequently, the profile of each air voids shown in Figure $5 \mathrm{~b}$ was obtained by conducting a searching calculation of the boundary position in binarization graph.

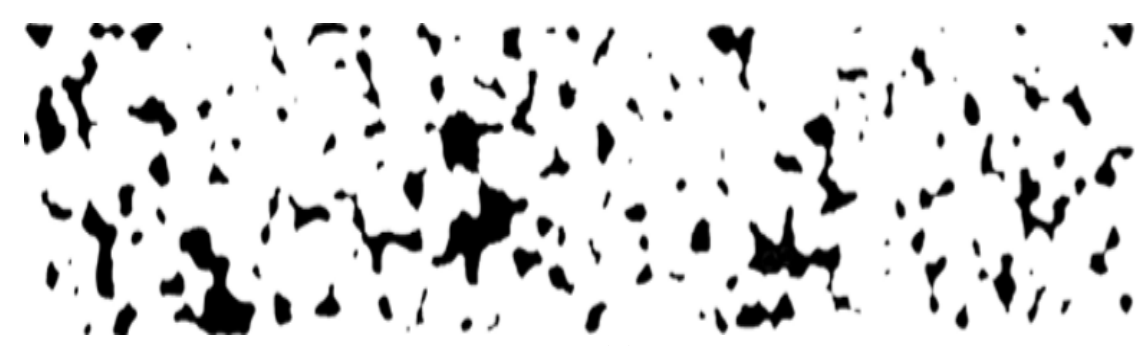

(a)
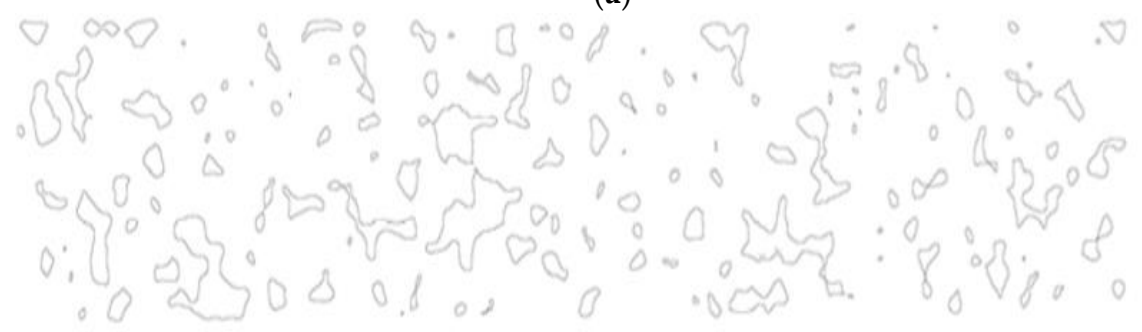

(b)

Figure 5. Image Process, (a) Image segmentation, (b) Voids extraction.

\section{Calculation}

Given that the resolution of images was consistent during the image process and the resolution unit was ppi, the area of each air voids can be calculated according to the number of pixels and the area of each pixel. Since each inch has a specific number of pixels, which depends on the resolution. Thus, the area of each pixel can be calculated on the area of each inch divided by the resolution, as shown in Equation (1). The area of each air voids can be calculated based on Equation (2). Alternatively, applying software Image J could also achieve the same results, the area of each air voids could be calculated automatically in the software.

$$
A_{p}=\left(\frac{25.4}{r}\right)^{2}
$$

where:

$A_{p}=$ The area of each pixel, $\mathrm{mm}^{2}$,

$r=$ resolution, ppi.

$$
A=n A_{p}=n\left(\frac{25.4}{r}\right)^{2}
$$

where:

$A=$ The area of each air voids, $\mathrm{mm}^{2}$,

$n=$ the number of pixels in each air voids.

In this study, all materials were considered to be non-spherical, and this is because the aggregates are non-spherical due to its corner angle, the air voids are almost all non-uniform after the mixture being compacted. In order to compare different non-uniform voids characteristics, the equivalent aperture 
was proposed to measure the voids uniformly. It was calculated to study the voids structure distribution in this study. Equation (3) indicates the calculation of equivalent aperture when transferring the voids area into a circle.

$$
D=2 \sqrt{\frac{A}{\pi}}
$$

where:

$D=$ equivalent aperture, $\mathrm{mm}$,

$A=$ The area of each air voids, $\mathrm{mm}^{2}$.

Equations (4) and (5) show the calculation of air voids and the average equivalent aperture of each section profile.

$$
V=\frac{\sum A}{A_{s}} \times 100 \%
$$

where:

$V=$ the air voids of each section profile, $\%$,

$A_{s}=$ area of each section profile, $\mathrm{mm}^{2}$ (Equal to total pixels areas).

$$
D_{\operatorname{avg}}=2 \sqrt{\frac{\sum A}{N \pi}}
$$

where:

$D_{\text {avg }}=$ average equivalent aperture of each section profile, $\mathrm{mm}$,

$A=$ the area of each air voids, $\mathrm{mm}^{2}$,

$N=$ number of air voids in each section profile.

In this study, to figure out the air voids distribution along both vertical and horizontal sections, the average value of voids number and content were used. To figure out the variations between different samples, the number and area of voids in each section were compared and analyzed.

\section{Results and Discussion}

\subsection{Vertical Voids Distribution}

Table 1 shows the voids numbers and equivalent aperture distribution. As Figure 6 shows, except for the equivalent aperture ranging from $0 \sim 2 \mathrm{~mm}$, the number of voids would decrease as the range of equivalent aperture increases. It means that under specific air voids, the larger the areas of the voids are, the smaller the number of them would be, which is probably because that it is more likely for materials to form small voids after rolling instead of large ones due to the compaction. Although the distribution of voids with equivalent aperture ranging from $0 \sim 2 \mathrm{~mm}$ does not show such a clear trend with that ranging from $2 \sim 4 \mathrm{~mm}$, this trend is apparent from the overall distribution. The total air voids number could also support this trend. In addition, it could be found that in all cases, the number of voids in relatively small equivalent aperture ranges account for a large proportion. In other words, a large number of voids in the specimens are small ones. Thus, from the vertical direction, the main voids of the material are those with equivalent aperture below $10 \mathrm{~mm}$ for OGFC-13, which account for more than $90 \%$ of the total number.

The correlations between the parameters in Table 1 and equivalent aperture ranges were studied and the results were shown in Table 1. It can be noticed that the number of voids has a high correlation with the equivalent aperture ranging from $0 \sim 2 \mathrm{~mm}$, whose $\mathrm{R}^{2}$ is 0.79 . As Figure 7 shows, as the total number of voids increases, the number of voids whose equivalent aperture ranges from $0 \sim 2 \mathrm{~mm}$ would increase accordingly. It supports the aforementioned trend that the number of small voids accounts for a large proportion of the total number. However, a poor correlation was found between the air 
voids content of each section and voids with equivalent aperture ranging from $0 \sim 2 \mathrm{~mm}$, indicating that although there are a lot of small voids in materials, they do not affect the air voids content remarkably. In fact, the void number with different equivalent aperture ranges in vertical sections has no apparent correlation with the air voids of each section and the highest $R^{2}$ is only 0.29 . It means the number of each vertical equivalent aperture range may not significantly impact the total air voids. From the determinant coefficient perspective, there is no significant difference between the small size voids which have a large amount and large size voids which only have a small amount. Therefore, it can be inferred that the overall air voids content may not be influenced by a single or several sizes of voids significantly.

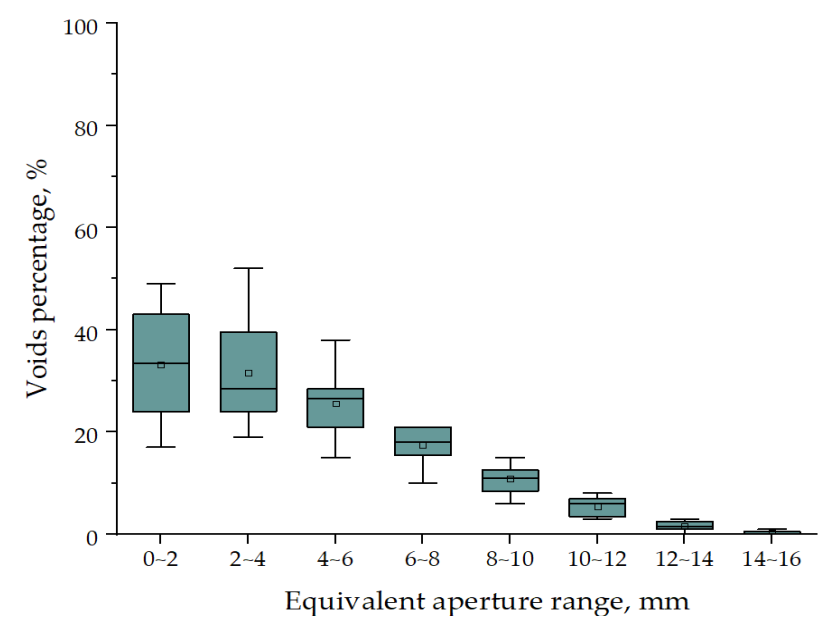

Figure 6. Voids number distribution along the vertical section.

Table 1. Coefficient Determinant Matrix.

\begin{tabular}{|c|c|c|c|c|c|c|c|c|}
\hline $\mathbf{R}^{2}$ & $\begin{array}{l}0 \sim 2 \mathrm{~mm} \\
\text { Voids } \\
\text { Number }\end{array}$ & $\begin{array}{l}2 \sim 4 \mathrm{~mm} \\
\text { Voids } \\
\text { Number }\end{array}$ & $\begin{array}{l}4 \sim 6 \mathrm{~mm} \\
\text { Voids } \\
\text { Number }\end{array}$ & $\begin{array}{c}6 \sim 8 \mathrm{~mm} \\
\text { Voids } \\
\text { Number }\end{array}$ & $\begin{array}{c}8 \sim 10 \mathrm{~mm} \\
\text { Voids } \\
\text { Number }\end{array}$ & $\begin{array}{l}10 \sim 12 \mathrm{~mm} \\
\text { Voids } \\
\text { Number }\end{array}$ & $\begin{array}{l}12 \sim 14 \mathrm{~mm} \\
\text { Voids } \\
\text { Number }\end{array}$ & $\begin{array}{c}14 \sim 16 \mathrm{~mm} \\
\text { Voids } \\
\text { Number }\end{array}$ \\
\hline $\begin{array}{c}\text { Total } \\
\text { Number of } \\
\text { voids }\end{array}$ & (+) 0.79 & (+) 0.49 & $(+) 0.47$ & (+) 0.16 & (+) 0.13 & (-) 0.01 & (-) 0.22 & 0.00 \\
\hline $\begin{array}{l}\text { Air voids of } \\
\text { each section } \\
(\%)\end{array}$ & $(+) 0.16$ & (+) 0.02 & $(+) 0.09$ & (+) 0.02 & (+) 0.21 & $(+) 0.29$ & (+) 0.01 & 0.00 \\
\hline
\end{tabular}

Note 1: The symbol in the bracket represents the positive (+)/negative (-) correlation.

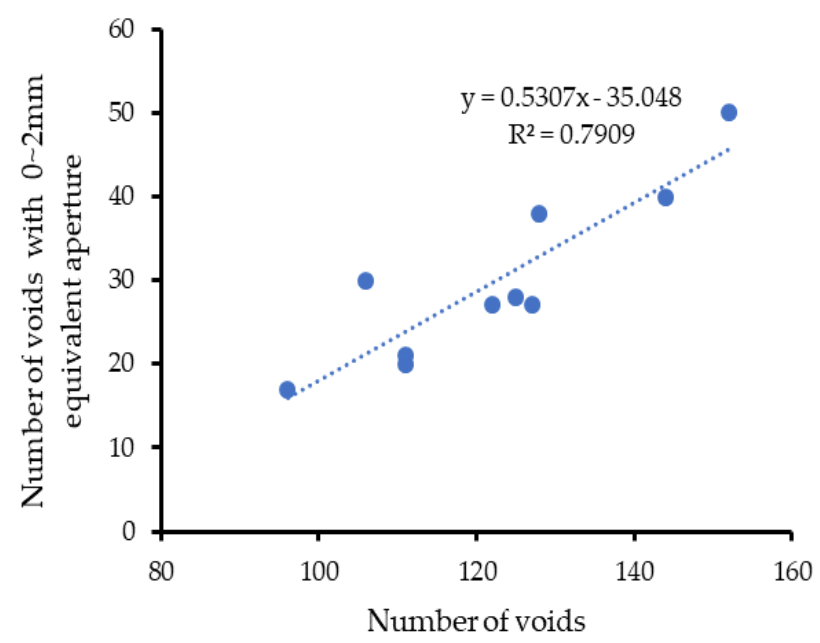

Figure 7. Correlation between the number of voids and that with $0 \sim 2 \mathrm{~mm}$ equivalent aperture. 
To further explore the relationship between voids and the equivalent aperture, the gradation of the voids number along the vertical section was drawn in Figure 8a,b. Each section in both OGFC samples shows a similar trend, which means the air voids number distribution of the material is relatively even. As the equivalent aperture range increases, the speed to accumulate voids number would decrease. When the equivalent aperture range reaches $8 \sim 10 \mathrm{~mm}$ in each section, the accumulated number of voids is close to the total number, which means that voids with the equivalent aperture below $10 \mathrm{~mm}$ account for almost all the voids. The relationship between the average accumulated voids and equivalent aperture range is shown in Figure $8 c$, a high correlation can be found in a quadratic polynomial with $\mathrm{R}^{2}$ of 0.98 . From the equation shown in Figure $8 \mathrm{c}$, the speed to accumulate voids number decreases as equivalent aperture increases. The cumulative function of the voids number correlates well with the Exp function with $R^{2}$ of 0.99 , which could be used to calculate the voids number of different sizes or accumulated voids number with a certain equivalent aperture range.

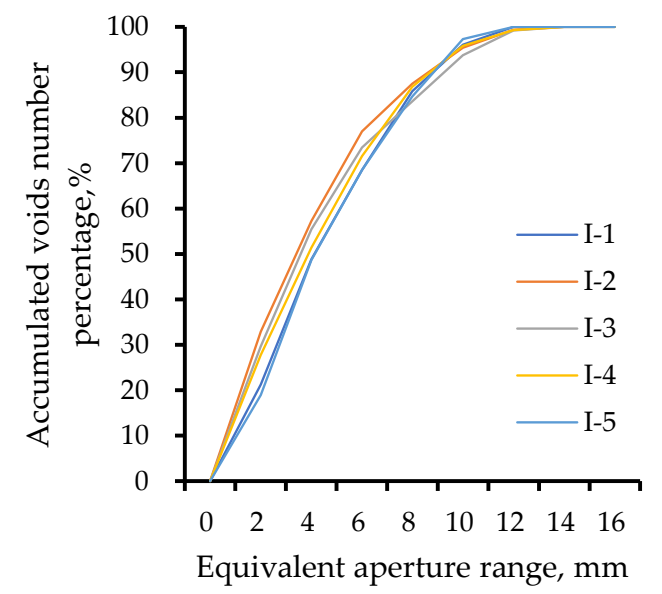

(a)

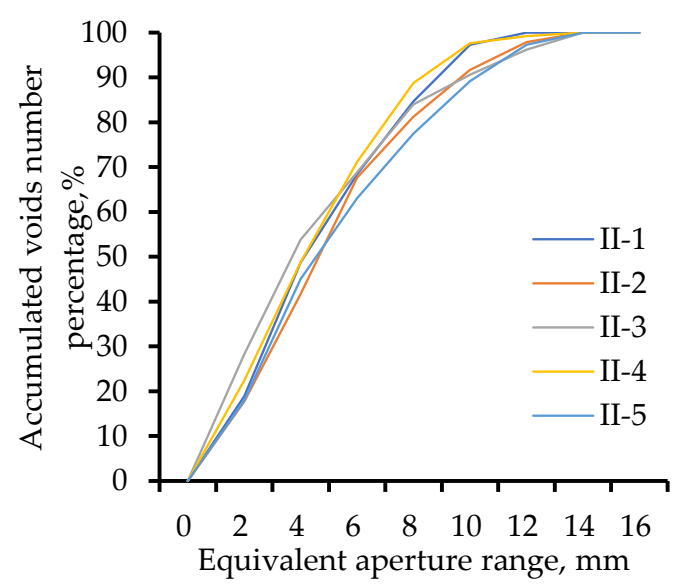

(b)

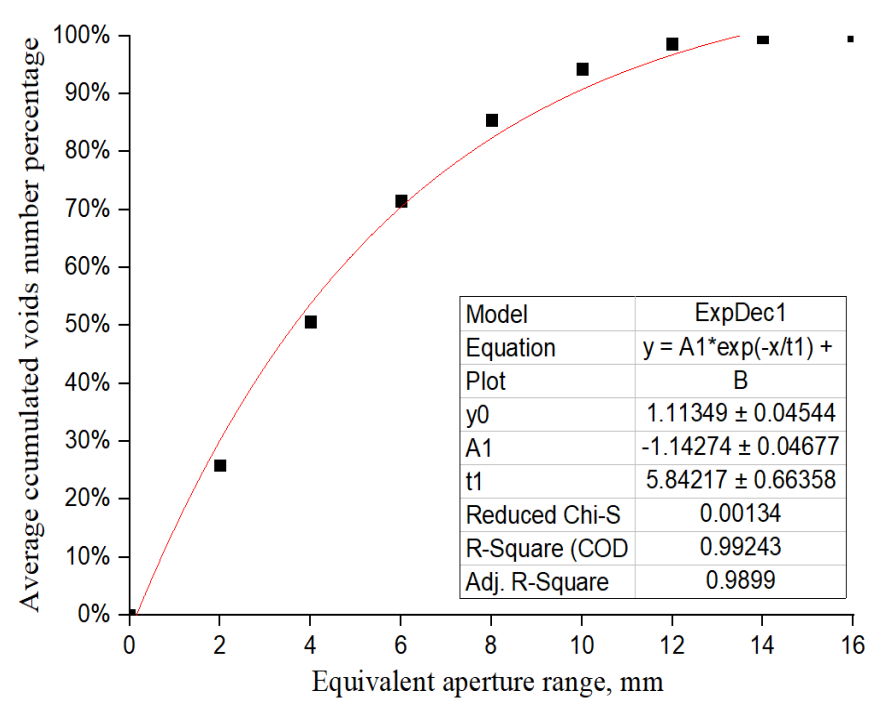

(c)

Figure 8. Relationship between accumulated number of voids and the equivalent aperture, (a) OGFC sample I, (b) OGFC sample II, (c) Average value of OGFC samples.

On the other hand, the relationship between the accumulated void areas and equivalent aperture range is shown in Figure 9a,b. As Figure 9a shows, each section of OGFC sample -I has a good consistency with others, with minor fluctuation on the equivalent aperture ranging from $6 \sim 8 \mathrm{~mm}$, $8 \sim 10 \mathrm{~mm}$ and 10 12 $\mathrm{mm}$. For the OGFC sample -II in Figure $9 \mathrm{~b}$, a similar trend could be found, while for the equivalent aperture ranging from $6 \sim 8 \mathrm{~mm}, 8 \sim 10 \mathrm{~mm}$, and $10 \sim 12 \mathrm{~mm}$, a more remarkable 
fluctuation could be noted. Figure $9 \mathrm{c}$ shows the relationship between average accumulated voids areas and equivalent aperture range, the fluctuation on the equivalent aperture ranging from $6 \sim 8$ $\mathrm{mm}, 8 \sim 10 \mathrm{~mm}$, and 10 12 $\mathrm{mm}$ is more apparent. As in vertical sections, the number of voids whose equivalent aperture ranges from $12 \sim 14 \mathrm{~mm}$ is few and there are no voids with the equivalent aperture ranging from $14 \sim 16 \mathrm{~mm}$, it is understandable that there is no large variation in accumulated voids areas. However, as aforementioned, as equivalent aperture increases, the number of voids would decrease, while the trend of accumulated voids areas differs from the accumulated voids number. Additionally, as the equivalent aperture range increases, the speed to accumulate voids areas would firstly increase then decrease, and the inflection point is obtained by calculated the point when the second derivative of the equation reaches 0 . The result of the inflection point is about $8 \mathrm{~mm}$, which means that the speed to accumulate voids area becomes the highest when the equivalent aperture is $8 \mathrm{~mm}$, indicating that those air voids account for the largest part of the total area. Before equivalent aperture reaches $8 \mathrm{~mm}$, the speed to accumulate number of voids decreases while the speed to accumulate voids area would increase. It means that before the equivalent aperture reaches $8 \mathrm{~mm}$, the contribution to the total voids area would become greater as the equivalent aperture increases, and then the contribution to the total voids area would decrease. The cumulative function of voids area fits DoseResp function well with $0.99 \mathrm{R}^{2}$, which could be used to calculate the proportion of voids area with a specific size or the accumulated voids area with a certain equivalent aperture range along the vertical direction.

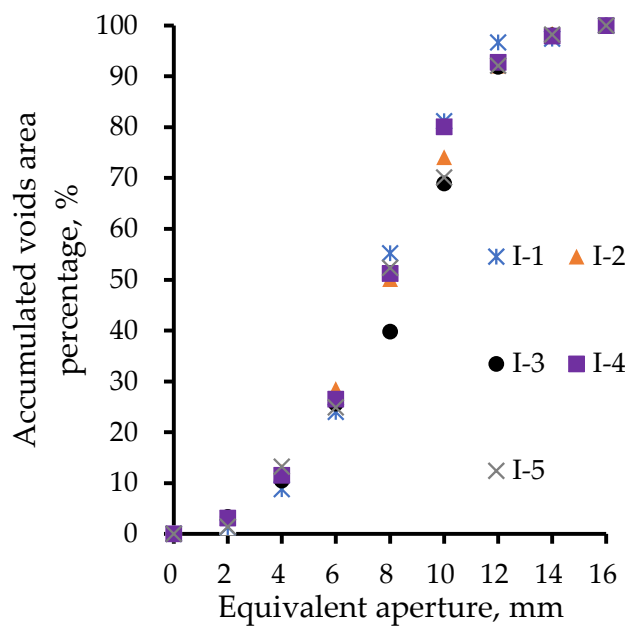

(a)

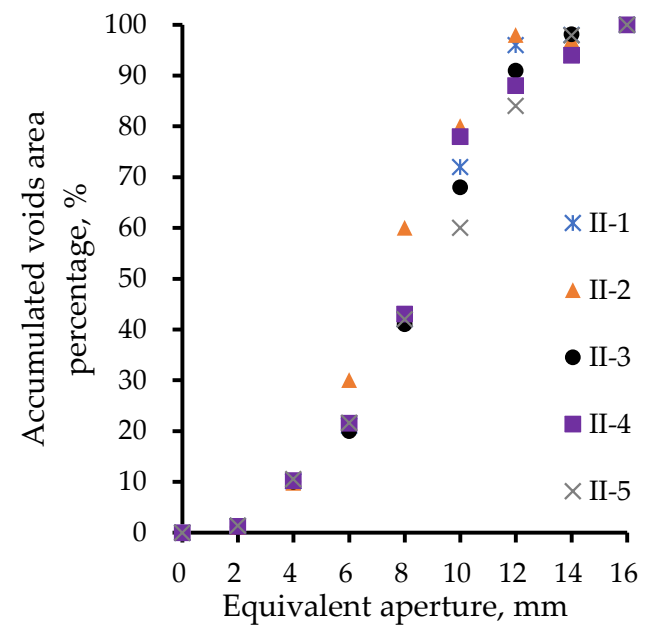

(b)

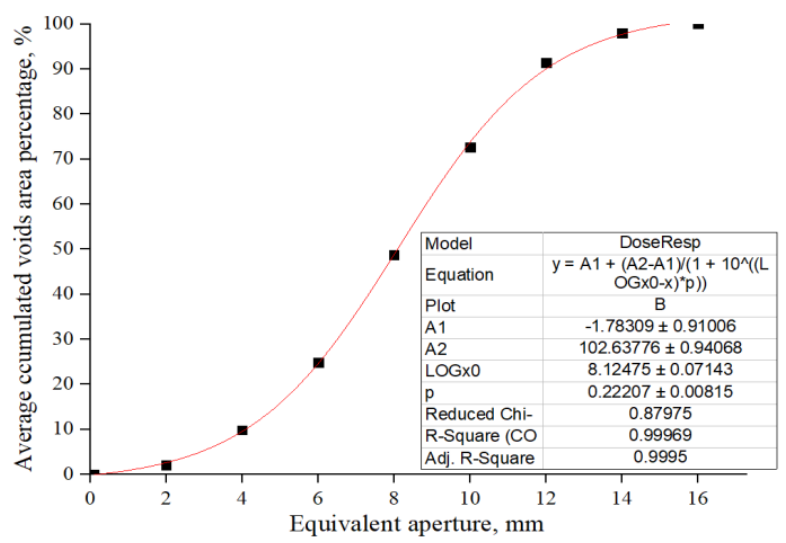

(c)

Figure 9. Relationship between accumulated voids area and the equivalent aperture, (a) OGFC sample I, (b) OGFC sample II, (c) Average value of OGFC samples. 


\subsection{Horizontal Voids Distribution}

As Figure 10 shows, a similar trend can be found as a vertical equivalent aperture range distribution. when the equivalent aperture is above $4 \mathrm{~mm}$, the number of voids would decrease as then range increases. For the range from $0 \sim 2 \mathrm{~mm}$ and $2 \sim 4 \mathrm{~mm}$, the numbers of voids are compatible. In addition, in Figure 10, it is more apparent that the number of voids with small equivalent aperture ranges account for a large proportion, which is more than $90 \%$ of the total voids number.

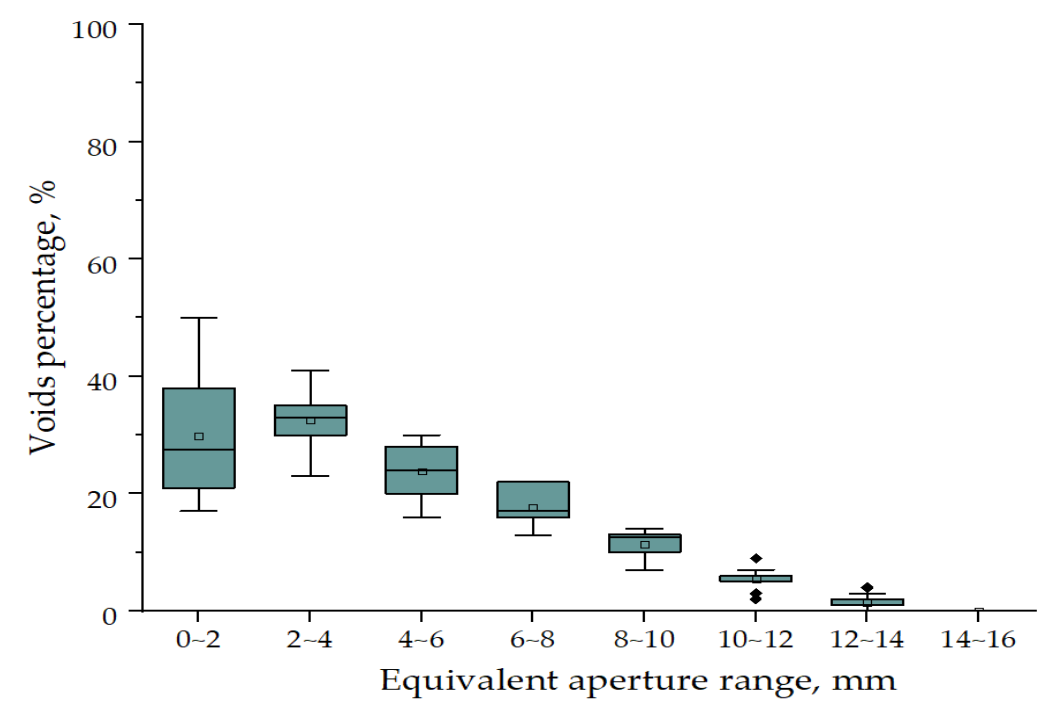

Figure 10. Voids number distribution along the horizontal section.

The correlations between the parameters in Table 2 and the equivalent aperture were studied, and the results were shown in Table 2. It can be noticed that in horizontal sections, the number of voids still has a high correlation with the equivalent aperture ranging from $0 \sim 2 \mathrm{~mm}$, whose $\mathrm{R}^{2}$ is 0.71 . As Figure 11 shows, as the total number of voids increases, the number of voids whose equivalent aperture ranges from $0 \sim 2 \mathrm{~mm}$ would increase. Therefore, in horizontal sections, the $0 \sim 2 \mathrm{~mm}$ equivalent aperture voids still account for a large proportion of the total voids. Similar to the vertical sections, the $0 \sim 2 \mathrm{~mm}$ equivalent aperture voids in the horizontal sections has a poor correlation with the air voids, while its $\mathrm{R}^{2}$ is the highest among all equivalent aperture ranges. In addition, in horizontal sections, the total air voids would not be impacted by one or several sizes of voids, which is similar to vertical sections.

Table 2. Coefficient Determinant Matrix.

\begin{tabular}{|c|c|c|c|c|c|c|c|c|}
\hline $\mathbf{R}^{2}$ & $\begin{array}{l}0 \sim 2 \mathrm{~mm} \\
\text { Voids } \\
\text { Number }\end{array}$ & $\begin{array}{l}2 \sim 4 \mathrm{~mm} \\
\text { Voids } \\
\text { Number }\end{array}$ & $\begin{array}{l}4 \sim 6 \mathrm{~mm} \\
\text { Voids } \\
\text { Number }\end{array}$ & $\begin{array}{l}6 \sim 8 \mathrm{~mm} \\
\text { Voids } \\
\text { Number }\end{array}$ & $\begin{array}{l}8 \sim 10 \mathrm{~mm} \\
\text { Voids } \\
\text { Number }\end{array}$ & $\begin{array}{l}10 \sim 12 \mathrm{~mm} \\
\text { Voids } \\
\text { Number }\end{array}$ & $\begin{array}{l}\text { 12 14 mm } \\
\text { Voids } \\
\text { Number }\end{array}$ & $\begin{array}{l}\text { 14 16 mm } \\
\text { Voids } \\
\text { Number }\end{array}$ \\
\hline $\begin{array}{l}\text { Total Number } \\
\text { of voids }\end{array}$ & (+) 0.71 & $(+) 0.55$ & $(+) 0.05$ & (+) 0.04 & (+) 0.02 & (+) 0.05 & (+) 0.39 & $(+) 0.22$ \\
\hline $\begin{array}{c}\text { Air voids of } \\
\text { each section } \\
(\%)\end{array}$ & (+) 0.27 & (+) 0.15 & (+) 0.04 & (+) 0.01 & (+) 0.22 & (+) 0.03 & (+) 0.20 & (+) 0.01 \\
\hline
\end{tabular}




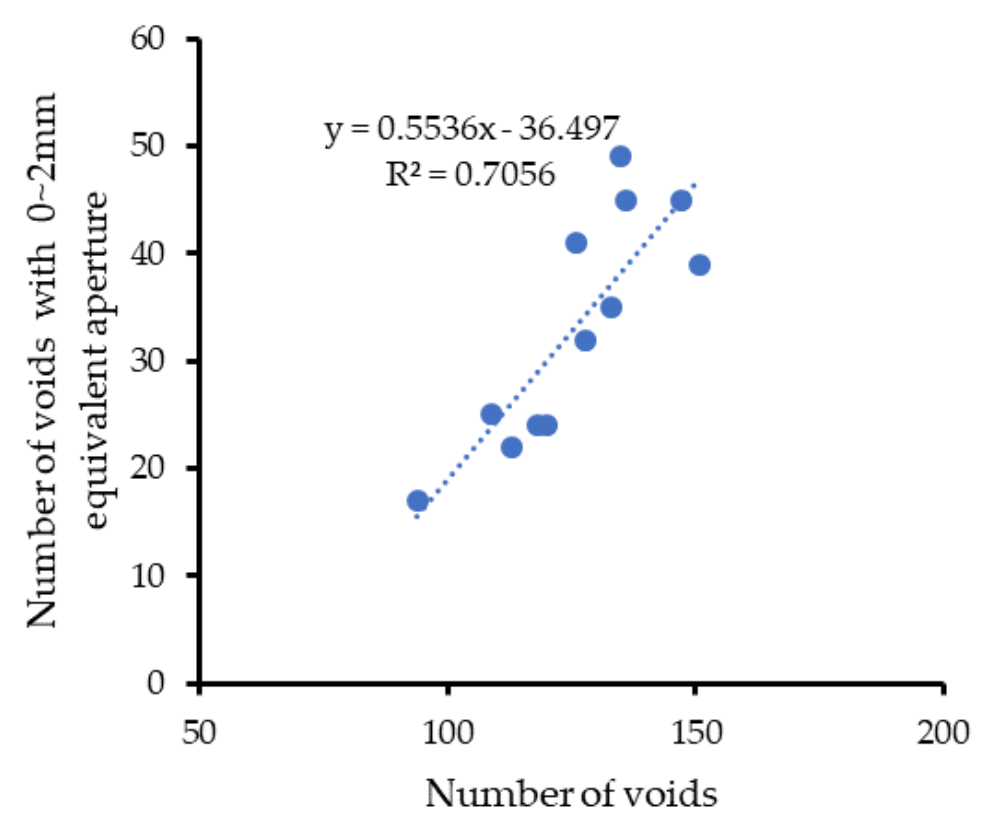

Figure 11. Voids number distribution along the horizontal section.

The gradation of voids number in OGFC samples along the horizontal sections was drawn in Figure 12a,b. Each section in both samples shows a similar trend. As the equivalent aperture increases, the speed to accumulate voids number would decrease. When the equivalent aperture range reaches $8 \sim 10 \mathrm{~mm}$ in each section, the accumulated number of voids is close to the total number, which is similar to the vertical cases. The relationship between the average accumulated voids area and the equivalent aperture is shown in Figure 12c, a high correlation can be also found in a quadratic polynomial with $\mathrm{R}^{2}$ of 0.98. From Figure 12c, the speed to accumulate voids number would decrease as equivalent aperture increases, which is similar to the cases in vertical sections.

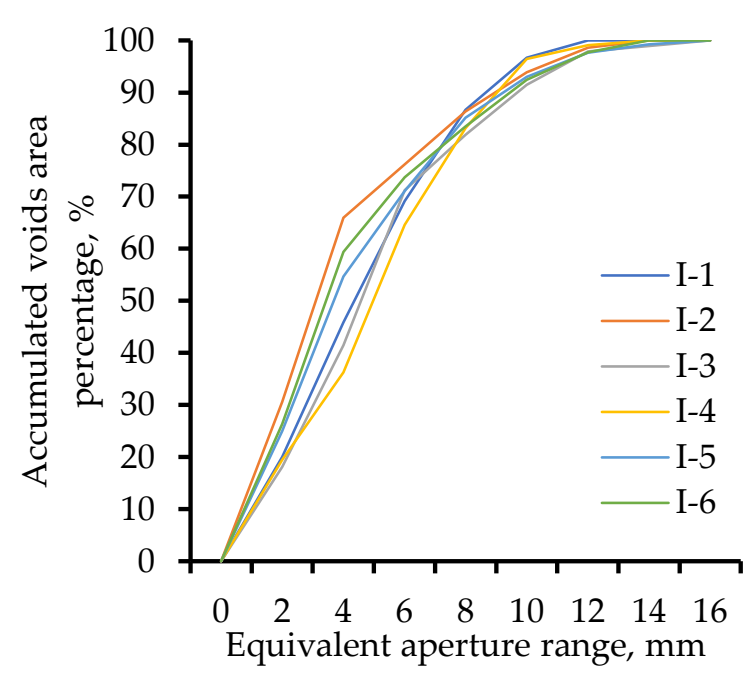

(a)

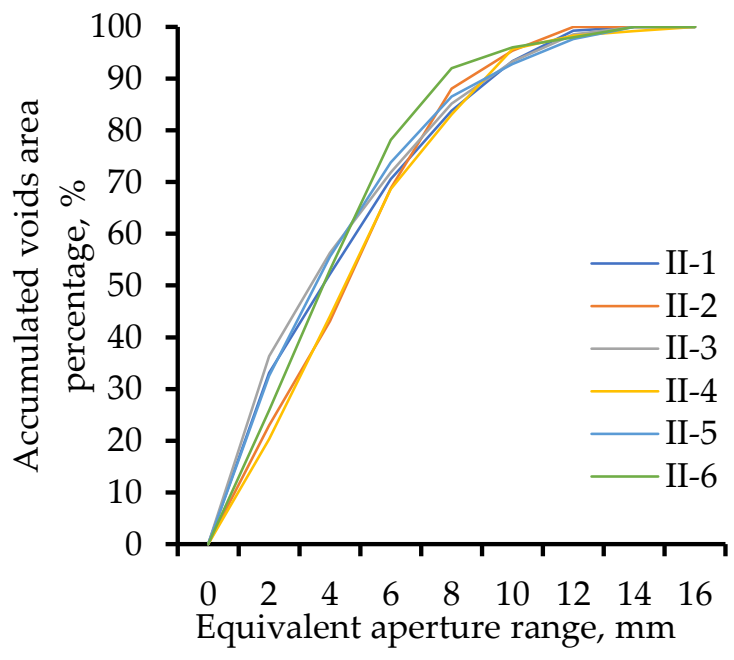

(b)

Figure 12. Cont. 


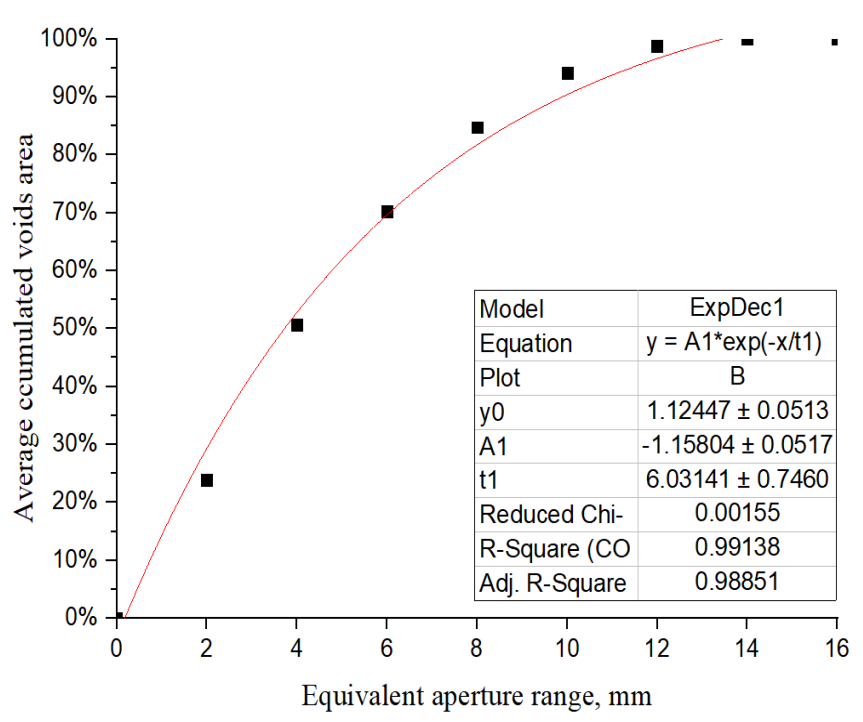

(c)

Figure 12. Relationship between accumulated voids area and the equivalent aperture, (a) OGFC sample I, (b) OGFC sample II, (c) Average value of OGFC samples.

The relationship between the accumulated voids areas and equivalent aperture range along horizontal sections is shown in Figure 13a,b. It could be found that when the equivalent aperture ranges from $4 \sim 6 \mathrm{~mm}, 6 \sim 8 \mathrm{~mm}, 8 \sim 10 \mathrm{~mm}, 10 \sim 12 \mathrm{~mm}$, and $12 \sim 14 \mathrm{~mm}$, the accumulated voids areas have a relatively high fluctuation. Also, the overall trend is that as the equivalent aperture increases, the speed to accumulate voids areas would firstly increase then decrease, and the inflection point occurs when equivalent aperture reaches about $8 \mathrm{~mm}$, which is similar with the vertical cases. Figure 13c shows the relationship between average accumulated voids areas and the equivalent aperture, the fluctuation on the equivalent aperture ranging from $6 \sim 8 \mathrm{~mm}, 8 \sim 10 \mathrm{~mm}$, and 10 12 $\mathrm{mm}$ are notable and the trend is the same as separate ones. In addition, the voids with the equivalent aperture ranging from $8 \sim 12 \mathrm{~mm}$ are the most important to the voids structure distribution as well as vertical sections because they contribute a larger proportion to the total voids area. The cumulative function of voids area also fits DoseResp function well with $0.99 \mathrm{R}^{2}$. It could be used to calculate the proportion of voids area with a specific size or the accumulated voids area with a certain equivalent aperture range along the horizontal direction.

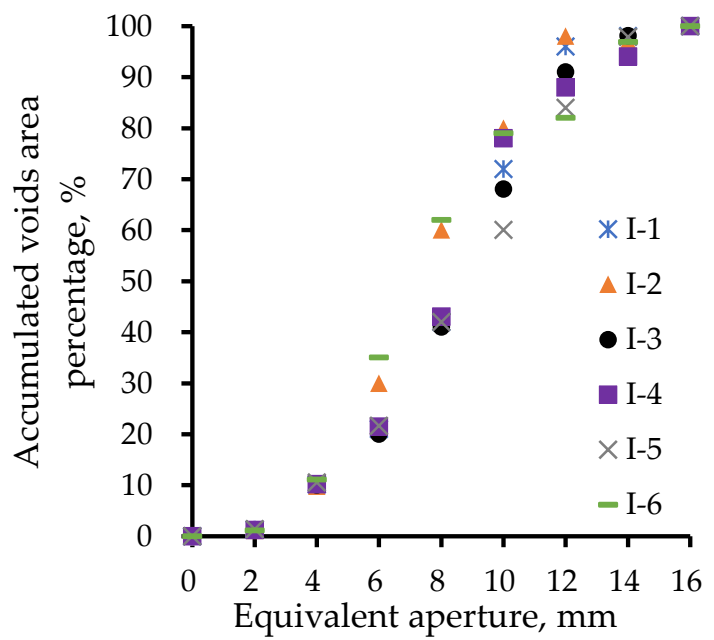

(a)

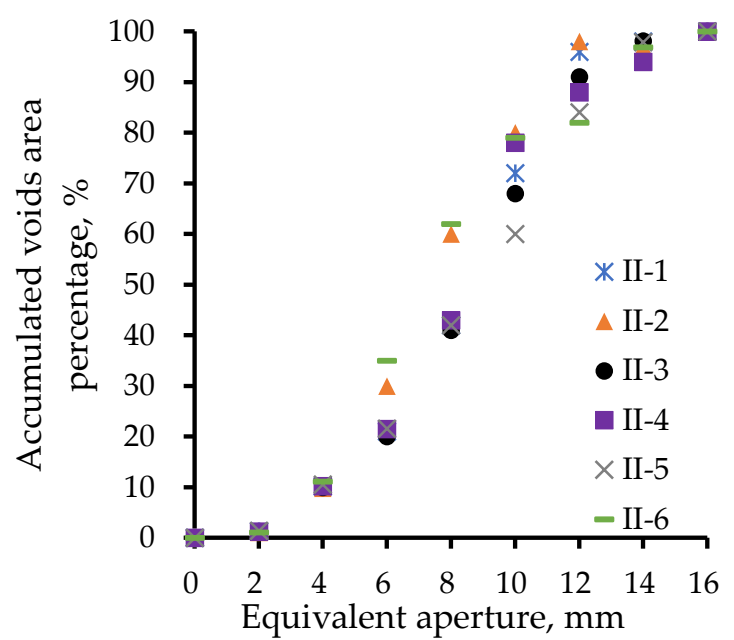

(b)

Figure 13. Cont. 


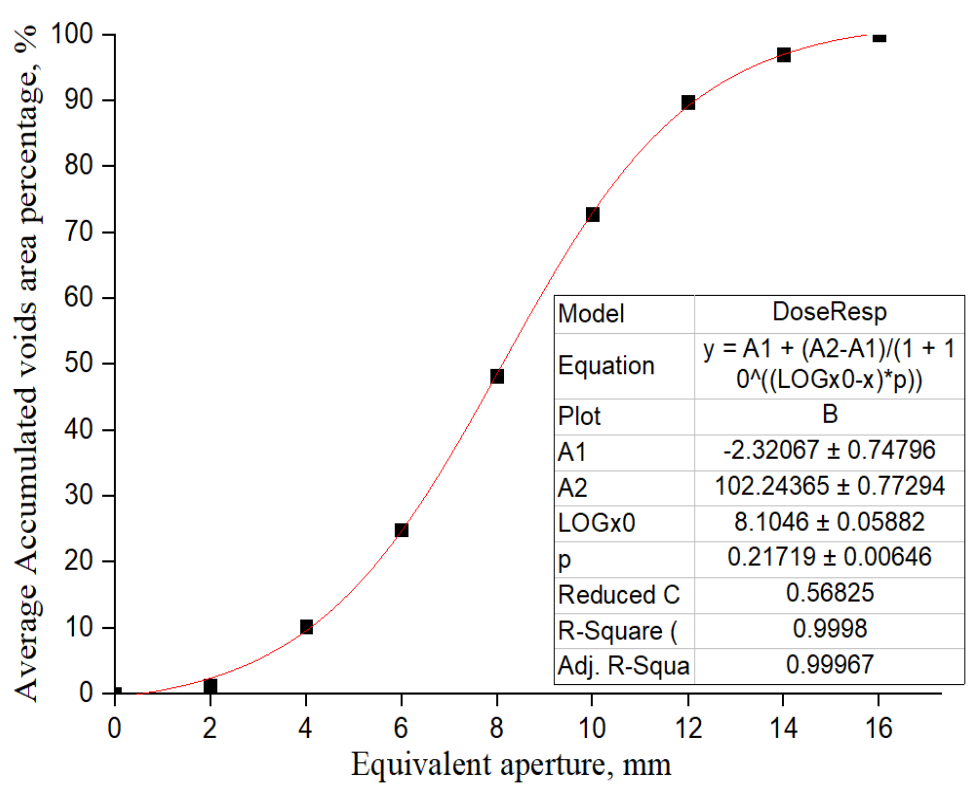

(c)

Figure 13. The relationship between the accumulated voids areas and the equivalent aperture along horizontal sections, (a) OGFC sample I, (b) OGFC sample II, (c) Average value of OGFC samples.

\section{Conclusions}

This paper studied the voids structure distribution inside the materials. The digital camera processing was adopted to obtain the vertical and horizontal section profiles of the materials and software such as MATLAB and Photoshop were used to process the images. Given that the voids inside the materials are irregular and complicated, equivalent aperture was proposed in this study to simplify the voids. The conclusions are summarized as following:

- In both vertical and horizontal sections, voids with the equivalent aperture ranging from $0 \sim 4 \mathrm{~mm}$ account for a large proportion, and when the equivalent aperture is beyond $4 \mathrm{~mm}$, the total number of voids would decrease as equivalent aperture increases.

- In both vertical and horizontal sections, the number of voids with the equivalent aperture ranging from $0 \sim 2 \mathrm{~mm}$ has a great impact on the total voids number. However, large amounts of small voids do not significantly affect the overall air voids content. In addition, the number of voids with different equivalent apertures do not have a good correlation with the air voids content, no matter in vertical or horizontal sections. The air voids content would not be affected significantly by a single or several sizes of voids.

- The accumulated number of voids is close to the total voids number when the equivalent aperture reaches $10 \mathrm{~mm}$ in both vertical and horizontal cases, and voids with equivalent aperture ranging from $0 \sim 10 \mathrm{~mm}$ comprise most of the voids area.

- As the increase in the equivalent aperture, the speed to accumulate voids area would firstly increase then decrease, the trend could be found in both vertical and horizontal cases. The inflection point would occur when the equivalent aperture is around $8 \mathrm{~mm}$. For the vertical section, the speed to accumulate voids area has a high fluctuation when the equivalent aperture range is from $6 \sim 12 \mathrm{~mm}$, while for horizontal sections, the range is from $4 \sim 14 \mathrm{~mm}$.

- The contribution of the voids to total voids area increases as the equivalent aperture size increases, and it would approach the peak when the equivalent aperture reaches about $8 \mathrm{~mm}$.

- Due to the limitation of the technique used in this study, the air voids discussed including both connected and closed voids, which are difficult to differentiate and need further research. Additionally, the equivalent aperture method proposed in this study also needs further validation. 
Author Contributions: Conceptualization, G.X. and X.H.; methodology, X.H. and T.M.; validation, G.X. and W.Z.; investigation, W.Z and X.C.; writing—original draft preparation, X.C.; writing—review and editing, G.X and T.M.

Funding: This research was funded by the National Natural Science Foundation of China, grant number 51808116 and Natural Science Foundation of Jiangsu Province, grant number BK20180404.

Conflicts of Interest: The authors declare no conflict of interest.

\section{References}

1. Seo, Y.; El-Haggan, O.; King, M.; Lee, J.S.; Kim, R.Y. Air void models for the dynamic modulus, fatigue cracking, and rutting of asphalt concrete. J. Mater. Civil Eng. 2007, 19, 874-883. [CrossRef]

2. Tashman, L.; Masad, E.; D'Angelo, J.; Bukowski, J.; Harman, T. X-ray tomography to characterize air void distribution in superpave gyratory compacted specimens. Int. J. Pavement Eng. 2002, 3, 19-28. [CrossRef]

3. Ren, J.; Sun, L. Characterizing air void effect on fracture of asphalt concrete at low-temperature using discrete element method. Eng. Fract. Mech. 2017, 170, 23-43. [CrossRef]

4. Hu, J.; Liu, P.; Wang, D.; Oeser, M.; Tan, Y. Investigation on fatigue damage of asphalt mixture with different air-voids using microstructural analysis. Construct. Build. Mater. 2016, 125, 936-945. [CrossRef]

5. Arambula, E.; Masad, E.; Martin, A.E. Influence of air void distribution on the moisture susceptibility of asphalt mixes. J. Mater. Civil Eng. 2007, 19, 655-664. [CrossRef]

6. Cooley, L.A., Jr.; Brown, E.R.; Maghsoodloo, S. Development of critical field permeability and pavement density values for coarse-graded Superpave pavements. J. Transport. Res. Board 2001. [CrossRef]

7. Masad, E.; Jandhyala, V.K.; Dasgupta, N.; Somadevan, N.; Shashidhar, N. Characterization of air void distribution in asphalt mixes using X-ray computed tomography. J. Mater. Civil Eng. 2002, 14, 122-129. [CrossRef]

8. Masad, E.; Muhunthan, B.; Shashidhar, N.; Harman, T. Internal structure characterization of asphalt concrete using image analysis. J. Comput. Civil Eng. 1999, 13, 88-95. [CrossRef]

9. Dubois, V.; De La Roche, C.; Burban, O. Influence of the compaction process on the air void homogeneity of asphalt mixtures samples. Construct. Build. Mater. 2010, 24, 885-897. [CrossRef]

10. Castillo, D.; Caro, S. Probabilistic modeling of air void variability of asphalt mixtures in flexible pavements. Construct. Build. Mater. 2014, 61, 138-146. [CrossRef]

11. Chehab, G.R.; O'Quinn, E.; Kim, Y.R. Specimen geometry study for direct tension test based on mechanical tests and air void variation in sgc-compacted asphalt concrete specimens. Transport. Res. Record J. Transport. Res. Board. 2000, 1723, 125-132. [CrossRef]

12. Onifade, I.; Jelagin, D.; Guarin, A.; Birgisson, B.; Kringos, N. Asphalt internal structure characterization with X-ray computed tomography and digital image processing. Multi-Scale Model. Charact. Infrastruct. Mater. 2013, 139-158.

13. Wu, S.; Yang, J.; Yang, R.; Zhu, J.; Liu, S.; Wang, C. Investigation of microscopic air void structure of anti-freezing asphalt pavement with X-ray CT and MIP. Construct. Build. Mater. 2018, 178, 473-483. [CrossRef]

14. Zhang, Y.; Verwaal, W.; Van de Ven, M.F.C.; Molenaar, A.A.A.; Wu, S.P. Using high-resolution industrial CT scan to detect the distribution of rejuvenation products in porous asphalt concrete. Construct. Build. Mater. 2015, 100, 1-10. [CrossRef]

15. Wang, H.; Wang, J.; Chen, J. Micromechanical analysis of asphalt mixture fracture with adhesive and cohesive failure. Eng. Fract. Mech. 2014, 132, 104-119. [CrossRef]

16. Moriyoshi, A.; Jin, T.; Nakai, T.; Ishikawa, H. Evaluation methods for porous asphalt pavement in service for fourteen years. Construct. Build. Mater. 2013, 42, 190-195. [CrossRef]

17. Moriyoshi, A.; Jin, T.; Nakai, T.; Ishikawa, H.; Tokumitsu, K.; Kasahara, A. Construction and pavement properties after seven years in porous asphalt with long life. Construct. Build. Mater. 2014, 50, 401-413. [CrossRef]

18. Chen, J.; Chu, R.; Wang, H.; Xie, P. Experimental measurement and microstructure-based simulation of thermal conductivity of unbound aggregates. Construct. Build. Mater. 2018, 189, 8-18. [CrossRef]

19. Zhang, Y.; Ma, T.; Ling, M.; Zhang, D.Y.; Huang, X.M. Prediction of Dynamic Shear Modulus of Asphalt Mastics by Using the Discretized Element Simulation and Reinforcement Mechanisms. J. Mater. Civil Eng. 2019, 31, 04019163. [CrossRef] 
20. Ding, X.H.; Ma, T.; Huang, X.M. Discrete-Element Contour-Filling Modeling Method for Micro-and MacroMechanical Analysis of Aggregate Skeleton of Asphalt Mixture. J. Transport. Eng. 2019, 145, 04018056.

21. Zhang, Y.; Ma, T.; Ling, M.; Huang, X.M. Mechanistic Sieve Size Classification of Aggregate Gradation by Characterizing Load Carrying Capacity of Inner Structures. J. Eng. Mech. 2019, 145, 04019069. [CrossRef]

22. Kose, S.; Guler, M.; Bahia, H.; Masad, E. Distribution of strains within binders in HMA using imaging and finite element techniques, Transportation Research Record. J. Transport. Res. Board 2000, 1728, 21-27. [CrossRef]

23. Jiang, J.; Ni, F.; Dong, Q.; Yao, L.; Ma, X. Investigation of the internal structure change of two-layer asphalt mixtures during the wheel tracking test based on 2D image analysis. Construct. Build. Mater. 2019, 209, 66-76. [CrossRef]

24. You, Z.; Adhikari, S.; Kutay, M.E. Dynamic modulus simulation of the asphalt concrete using the x-ray computed tomography images. Mater. Struct. 2009, 42, 617-630. [CrossRef]

25. Shashidhar, N. X-ray Tomography of Asphalt Concrete; Transportation Research Record 1681; National Research Council: Washington, DC, USA, 2000; pp. 186-191. [CrossRef]

26. Mahmud, M.Z.H.; Hassan, N.A.; Hainin, M.R.; Ismail, C.R. Microstructural investigation on air void properties of porous asphalt using virtual cut section. Construct. Build. Mater. 2017, 155, 485-494. [CrossRef]

27. Zhao, P.; Li, Y. Grain counting method based on image processing. In Proceedings of the Information Engineering and Computer Science 2009 International Conference, Wuhan, China, 19-20 December 2009.

28. Wang, W.; Wang, L. An image processing method for grains counting. In System Simulation and Scientific Computing; Springer: Berlin/Heidelberg, Germany, 2012. [CrossRef]

29. Leavline, E.J.; Singh, D.A.A.G. On teaching digital image processing with MATLAB. Am. J. Signal Process. 2014, 4, 7-15.

30. Kreft, M.; Milisav, I.; Potokar, M.; Zorec, R. Automated high through-put colocalization analysis of multichannel confocal images. Comput. Methods Programs Biomed. 2004, 74, 63-67. [CrossRef]

(C) 2019 by the authors. Licensee MDPI, Basel, Switzerland. This article is an open access article distributed under the terms and conditions of the Creative Commons Attribution (CC BY) license (http://creativecommons.org/licenses/by/4.0/). 